\title{
CORRECTION
}

\section{Correction to: A Comprehensive Review on the Role of Genetic Factors in the Pathogenesis of Migraine}

\author{
Kaveh Ebrahimzadeh $^{1} \cdot$ Mahdi Gholipour $^{2} \cdot$ Mohammad Samadian $^{1} \cdot$ Mohammad Taheri $^{3}$ (D) $\cdot$ Soudeh Ghafouri-Fard $^{4}$
}

Published online: 23 March 2021

○) Springer Science+Business Media, LLC, part of Springer Nature 2021

\section{Correction to: Journal of Molecular Neuroscience https://doi.org/10.1007/s12031-020-01788-1}

The original version of this article unfortunately contained a mistake in the Authorgroup section. Kaveh Ebrahimzadeh's family name was misspelled as "Ebahimzadeh".
Publisher's Note Springer Nature remains neutral with regard to jurisdictional claims in published maps and institutional affiliations.

The original article can be found online at https://doi.org/10.1007/ s12031-020-01788-1.

Mohammad Taheri

mohammad823@yahoo.com

$\triangle$ Soudeh Ghafouri-Fard

s.ghafourifard@sbmu.ac.ir

1 Skull Base Research Center, Loghman Hakim Hospital, Shahid Beheshti University of Medical Sciences, Tehran, Iran

2 Department of Medical Genetics, Shahid Beheshti University of Medical Sciences, Tehran, Iran

3 Urology and Nephrology Research Center, Shahid Beheshti University of Medical Sciences, Tehran, Iran

4 Urogenital Stem Cell Research Center, Shahid Beheshti University of Medical Sciences, Tehran, Iran 